\title{
Regulation of fibrillins and modulators of TGF $\beta$ in fetal bovine and human ovaries
}

\author{
Nicole A Bastian, Rosemary A Bayne², Katja Hummitzsch, Nicholas Hatzirodos¹, \\ Wendy M Bonner ${ }^{1}$, Monica D Hartanti ${ }^{1}$, Helen F Irving-Rodgers ${ }^{1,3}$, Richard A Anderson ${ }^{2}$ \\ and Raymond J Rodgers ${ }^{1}$ \\ ${ }^{1}$ Discipline of Obstetrics and Gynaecology, School of Medicine, Robinson Research Institute, The University of \\ Adelaide, Adelaide, South Australia, Australia, ${ }^{2}$ Medical Research Council Centre for Reproductive Health, \\ University of Edinburgh, Queen's Medical Research Institute, Edinburgh, UK and ${ }^{3}$ School of Medical Science, \\ Griffith University, Gold Coast Campus, Southport, Queensland, Australia
}

Correspondence should be addressed to R J Rodgers; Email: ray.rodgers@adelaide.edu.au

\begin{abstract}
Fibrillins 1-3 are stromal extracellular matrix proteins that play important roles in regulating TGF $\beta$ activity, which stimulates fibroblasts to proliferate and synthesize collagen. In the developing ovary, the action of stroma is initially necessary for the formation of ovigerous cords and subsequently for the formation of follicles and the surface epithelium of the ovary. FBN3 is highly expressed only in early ovarian development and then it declines. In contrast, $F B N 1$ and 2 are upregulated in later ovarian development. We examined the expression of $F B N 1-3$ in bovine and human fetal ovaries. We used cell dispersion and monolayer culture, cell passaging and tissue culture. Cells were treated with growth factors, hormones or inhibitors to assess the regulation of expression of $F B N 1-3$. When bovine fetal ovarian tissue was cultured, $F B N 3$ expression declined significantly. Treatment with TGF $\beta-1$ increased $F B N 1$ and $F B N 2$ expression in bovine fibroblasts, but did not affect $F B N 3$ expression. Additionally, in cultures of human fetal ovarian fibroblasts (9-17 weeks gestational age), the expression of $F B N 1$ and $F B N 2$ increased with passage, whereas $F B N 3$ dramatically decreased. Treatment with activin A and a TGF $\beta$ family signaling inhibitor, SB431542, differentially regulated the expression of a range of modulators of TGF $\beta$ signaling and of other growth factors in cultured human fetal ovarian fibroblasts suggesting that TGF $\beta$ signaling is differentially involved in the regulation of ovarian fibroblasts. Additionally, since the changes in FBN1-3 expression that occur in vitro are those that occur with increasing gestational age in vivo, we suggest that the fetal ovarian fibroblasts mature in vitro. Reproduction (2016) 152 127-137
\end{abstract}

\section{Introduction}

Fibroblasts or stromal cells are of mesenchymal origin (Wong et al. 2007) and are a major cell type present in the stroma of many organs (Birchmeier \& Birchmeier 1993). They play an important role in the production and deposition of collagen in tissues (Varga et al. 1987, Christner \& Ayitey 2006) and ensure proper organ development and function (Saxen \& Sariola 1987, Birchmeier \& Birchmeier 1993). Perturbations within the stroma can result in defects in the functions of organs such as pulmonary fibrosis (Rock et al. 2011), cardiac fibrosis (Chen et al. 2000), renal fibrosis (Ito et al. 1998) and polycystic ovary syndrome (PCOS) (Hughesdon 1982).

Fibroblasts are activated by a profibrotic cytokine, TGF $\beta$ (Roberts et al. 1986, Chen et al. 2000, Raja-Khan et al. 2014). There are three TGF $\beta$ s secreted as inactive latent homodimeric complexes of precursor molecules each consisting of a signal peptide, a latency-associated peptide (LAP) and a mature peptide (Saharinen et al. 1999). These LAPs form covalent disulfide bonds with other chaperone proteins called latent TGF $\beta$-binding proteins (LTBPs) (Saharinen et al. 1999), specifically LTBP1, LTBP3 and LTBP4 (Isogai et al. 2003). LTBPs also play a role in regulating the secretion of latent TGF $\beta$ from cells and targeting latent TGF $\beta$ to the extracellular matrix (ECM) (Taipale et al. 1994, Isogai et al. 2003), where glycoproteins called fibrillins are present.

Fibrillins are major structural components in stromal ECM (Ramirez \& Pereira 1999). In addition to their structural function, they regulate growth factor/cytokine activity by binding LTBPs 1 to 4 (Isogai et al. 2003, Zilberberg et al. 2012) and thus sequestering latent TGF $\beta$ in the ECM (Chaudhry et al. 2007). This is important for the regulation of TGF $\beta$ activation and bioavailability in the ECM (Saharinen et al. 1999, Chaudhry et al. 2007) and hence for stromal fibroblast function. TGF $\beta$ is only released from the ECM and activated via proteolytic cleavage (Saharinen et al. 1999). Activated TGF $\beta$ can then activate fibroblasts to proliferate and synthesize ECM proteins such as collagens and 
fibronectin (Fine \& Goldstein 1987, Varga et al. 1987, Leask \& Abraham 2004). In 2004, another member of the fibrillin family, fibrillin 3, was discovered (Corson et al. 2004). The expression of the $F B N 3$ gene was shown to be significantly higher in fetal compared with adult tissues of the same organs (Corson et al. 2004, Sabatier et al. 2010, Hatzirodos et al. 2011). Furthermore, in addition to humans, FBN3 is expressed in cows, sheep and chickens, but not in rodents (Corson et al. 2004).

Recent studies have proposed a new model of mammalian ovarian development, which emphasizes the importance of stromal penetration and expansion as crucial processes in the developing fetal bovine and human ovaries (Hummitzsch et al. 2013, 2015, Heeren et al. 2015). The stromal tissue first penetrates the developing ovary from the mesonephros, and while doing so, it subdivides and thus partitions the oogonia and the precursor gonadal-ridge epithelial (GREL) cells of the ovary into ovigerous cords. It then segregates the ovigerous cords into smaller groups of cells thus contributing to the formation of follicles. Finally, it penetrates to just below the surface of the ovary before spreading laterally, thus isolating some GREL cells at the surface of the ovary. These GREL cells then begin to form an epithelium on the surface. Throughout ovary development, the stroma expresses fibrillin genes, but different ones at different times. In the bovine and human, FBN1 is expressed during fetal ovarian development and increases significantly in the adult ovary (Hatzirodos et al. 2011). FBN2 is also expressed in fetal ovaries, but declines in the later stages of bovine fetal ovarian development and increases in the adult bovine ovary. In humans, FBN2 is expressed during fetal ovarian development but is very low in the adult ovary (Hatzirodos et al. 2011). FBN3 is highly expressed in the early bovine and human fetal ovary; however, its expression declines and is undetectable in adult bovine and human ovaries (Hatzirodos et al. 2011). Histochemical localization of fibrillin 3 revealed an extensive network of fibrillin 3 fibers in the stromal compartment, as it penetrates between ovigerous cords in fetal bovine and human ovaries (Hatzirodos et al. 2011, Hummitzsch et al. 2013). These findings suggest that fibrillin 3 plays a crucial role in the fetal ovary during early ovary development, when stromal tissue is expanding from the mesonephros into the developing ovary (Hatzirodos et al. 2011, Hummitzsch et al. 2013), but as development progresses, fibrillin 1 in particular becomes more important.

Although the stromal matrix protein fibrillin-3 appears to have an important role early in fetal development, in contrast to all other fibrillins, LTBPs and TGF $\beta$ molecules, there is very little knowledge about its regulation or function. A recent study by Davis et al. (2014) identified the promoters of the human fibrillin genes and the transcription factors that bind to these promoters (Davis et al. 2014). This study was heavily biased to adult tissues present in the FANTOM database at that time, thus limiting the information about the promoter of $F B N 3$ and identification of potential transcription factor-binding motifs present within this promoter. Interestingly, it was found that the transcription factor-binding motifs in the $F B N 3$ promoter do not overlap with those of the other two fibrillin genes (Davis et al. 2014). This would be consistent with the differential expression of the fibrillin genes seen in ovaries (Hatzirodos et al. 2011).

The FBN3 gene may be associated with the occurrence of PCOS (Urbanek et al. 2007). The PCOS ovary phenotype has the hallmarks of increased TGF $\beta$ activity with expanded stroma and collagen deposition (Hughesdon 1982). Additionally, the behavior of the specialized stromal thecal cells is altered in polycystic ovary syndrome, with increased steroidogenic activity (Nelson et al. 1999, Polla et al. 2003). Thus, aberrant FBN3 activity during fetal development could be related to the altered stroma phenotype in the PCOS ovary (Hatzirodos et al. 2011, Raja-Khan et al. 2014). In this study, our goals were to determine the factors that affect FBN1-3 expression in human and bovine fetal ovaries.

\section{Materials and methods}

\section{Bovine fetal tissues}

Bovine fetal ovaries from a range of gestational ages were collected from fetuses of Bos taurus cows from a local abattoir (Thomas Foods International, Murray Bridge, SA, Australia). The crown-rump length of the fetuses was measured to determine the approximate ages of fetuses (Russe 1983), and the fetal ovaries were transported on ice in Hank's balanced salt solution containing $\mathrm{Mg}^{2+}$ and $\mathrm{Ca}^{2+}$ ( $\mathrm{HBSS}^{+/+}$; Sigma-Aldrich) to the laboratory. The connective tissue surrounding the fetal ovaries was removed and a small portion of the ovaries was excised and frozen at $-80^{\circ} \mathrm{C}$ for subsequent RNA extraction. The ovaries were rinsed once in $70 \%$ ethanol and twice in $\mathrm{HBSS}^{+/+}$and then dissected into small pieces and minced with a scalpel. The fetal ovaries were digested in $3-5 \mathrm{~mL}$ of $1 \mathrm{mg} / \mathrm{mL}$ collagenase type I (GIBCO/ Life Technologies Australia Pty Ltd) in $\mathrm{HBSS}^{+/+}$ at $37^{\circ} \mathrm{C}$ shaking at 150 r.p.m. The durations of digestion for the fetal ovaries depended on the crown-rump lengths of the fetuses. After the first digestion, the samples were centrifuged at $300 \mathrm{~g}$ for $5 \mathrm{~min}$ and the supernatant was removed. The samples were then digested in $2 \mathrm{~mL}$ of $0.025 \%$ trypsin/EDTA (GIBCO/ Life Technologies) in Hank's balanced salt solution without $\mathrm{Mg}^{2+}$ and $\mathrm{Ca}^{2+}\left(\mathrm{HBSS}^{-1}\right.$; Sigma-Aldrich) for $5 \mathrm{~min}$ at $37^{\circ} \mathrm{C}$ at 150 r.p.m. After centrifugation at $300 \mathrm{~g}$ for $5 \mathrm{~min}$, the cell pellets were resuspended in DMEM/F12 medium containing 5\% FCS, $1 \%$ penicillin and streptomycin sulfate, and $0.1 \%$ fungizone (all GIBCO/Life Technologies) and the cells were dispersed further by pipetting up and down. The fetal fibroblasts were cultured in 6 well plates or $10 \mathrm{~cm}$ Petri dishes at $38.5^{\circ} \mathrm{C}$ and $5 \% \mathrm{CO}_{2}$ until confluence. Once the fetal fibroblast cultures were confluent, the cells were detached by treatment with $0.25 \%$ trypsin/EDTA, the total number of viable cells was estimated with the trypan blue method using a hemocytometer and the cells subsequently stored in liquid nitrogen for later use. 


\section{Human fetal tissues}

Morphologically normal human fetal ovaries (9-17 weeks gestation) were obtained following medical termination of pregnancy. Maternal consent was obtained and the study was approved by the Lothian Research Ethics Committee (ref 08/ S1101/1). Gestational age of the fetuses was determined by ultrasound scan and by direct measurement of the fetal foot length. Extraneous tissue was removed from ovaries in HBSS (GIBCO/Life Technologies). Ovaries were manually dispersed under a dissection microscope using 19 gauge needles in $500 \mu \mathrm{L}$ of $10 \mathrm{mg} / \mathrm{mL}$ Collagenase IV (Sigma) in HBSS. The tissue/collagenase suspension was incubated in a thermomixer at $37^{\circ} \mathrm{C}$, shaking at 1000 r.p.m. for $10 \mathrm{~min}$ and pipetted up and down to ensure complete disaggregation of the tissue. Fifty microliters of DNase I ( $7 \mathrm{mg} / \mathrm{mL}$ HBSS; Sigma) were added to the suspension and incubated for a further $5 \mathrm{~min}$, shaking at $37^{\circ} \mathrm{C}$. The single-cell suspension was then centrifuged at $600 \mathrm{~g}$ for $5 \mathrm{~min}$ and the cell pellet was washed twice with $1 \mathrm{~mL}$ HBSS, centrifuging between each wash. The cell pellet was then resuspended in $1 \mathrm{~mL}$ DMEM (without phenol red) (Gibco/Life Technologies) supplemented with 10\% FCS, 2 mM L-glutamine, 1X MEM nonessential amino acids (NEAA; all Gibco/Life Technologies) and 1X penicillin/streptomycin/ amphotericin (Gibco/Life Technologies). The cell suspension was filtered through a $70 \mu \mathrm{m}$ filter and the resulting filtrate centrifuged. The cell pellet was resuspended in $1.2 \mathrm{~mL}$ culture medium. Two hundred microliters of the initial cell suspension were transferred to a separate fresh $1.5 \mathrm{~mL}$ tube and centrifuged.
The cell pellet was washed in $1 \mathrm{X}$ phosphate-buffered saline (PBS), resuspended in $350 \mu \mathrm{L}$ buffer RLT (Qiagen) with 2-mercapthoethanol (Sigma-Aldrich) and stored at $-80^{\circ} \mathrm{C}$ for RNA isolation $\left(\mathrm{T}_{0}\right)$. The remaining cells were cultured in 2 wells of a 12 well plate at $37^{\circ} \mathrm{C}$ and $5 \% \mathrm{CO}_{2}$ overnight. After $13-17 \mathrm{~h}$, the cells were washed twice with culture medium and these washes were collected and centrifuged. The pellet was washed with PBS, resuspended in $350 \mu \mathrm{L}$ buffer RLT plus 2-mercapthoethanol and stored at $-80^{\circ} \mathrm{C}$ for RNA isolation $\left(\mathrm{S}_{0}\right)$. Fresh culture medium was added to each well and the cells were cultured further until confluence (P0 culture). Once the cell cultures were confluent, the cells were detached through trypsination. An aliquot of the cells was collected for RNA extraction. The remaining cells were passaged into either a 6 well plate or $25 \mathrm{~cm}^{2}$ tissue culture flask. Passaging of cells and freezing down aliquots of cells in Bambanker (Anachem, Luton, Beds, UK), and freezing the medium were continued for several passages.

\section{Screening for possible regulators of FBN3 expression in cultured bovine fetal fibroblasts}

Bovine fetal fibroblasts ( $n=5$ from weeks 13, 14, 17, 19 and 33 of gestation) previously stored in liquid nitrogen were thawed and 30,000 cells/well were seeded in 24 well plates in DMEM/F12 medium containing 5\% FCS, 1\% penicillin and streptomycin sulfate and $0.1 \%$ fungizone, and incubated for $24 \mathrm{~h}$ at $38.5^{\circ} \mathrm{C}$ and $5 \% \mathrm{CO}_{2}$ until $60-70 \%$ confluence.

Table 1 Treatments for cultured bovine fetal ovarian fibroblasts.

\begin{tabular}{|c|c|c|c|}
\hline Category & Treatments & Concentration & Distributor \\
\hline \multirow[t]{9}{*}{ Hormones } & Dihydroxytestosterone & $100 \mathrm{ng} / \mathrm{mL}$ & Sigma-Aldrich \\
\hline & Estradiol & $100 \mathrm{ng} / \mathrm{mL}$ & Sigma-Aldrich \\
\hline & Progesterone & $100 \mathrm{ng} / \mathrm{mL}$ & Sigma-Aldrich \\
\hline & Testosterone & $100 \mathrm{ng} / \mathrm{mL}$ & Sigma-Aldrich \\
\hline & Prolactin & $1 \mu \mathrm{g} / \mathrm{mL}$ & $\begin{array}{l}\text { National Institute of Diabetes and Digestive and Kidney Diseases } \\
- \text { National Institutes of Health }\end{array}$ \\
\hline & Relaxin & $16.7 \mathrm{nM}$ & From Dr Ross Bathgate - University of Melbourne, Australia \\
\hline & Insulin-like protein 3 & $100 \mathrm{ng} / \mathrm{mL}$ & From Dr Ross Bathgate - University of Melbourne, Australia \\
\hline & Müllerian-inhibiting substance & $10 \mathrm{ng} / \mathrm{mL}$ & Biogen Idec Australia Pty Ltd, North Ryde, NSW, Australia \\
\hline & Insulin-like growth factor 1 & $30 \mathrm{ng} / \mathrm{mL}$ & GroPep Bioreagents Pty Ltd, Thebarton, SA, Australia \\
\hline \multirow[t]{2}{*}{ Prostaglandins } & Prostaglandin E2 & $1 \mu \mathrm{M}$ & Upjohn Company, Kalamazoo, MI, USA \\
\hline & Prostaglandin F2 $\alpha$ & $1 \mu \mathrm{M}$ & Upjohn Company, Kalamazoo, MI, USA \\
\hline \multirow[t]{2}{*}{ Cytokines } & Interleukin 1 beta & $50 \mathrm{ng} / \mathrm{mL}$ & $\begin{array}{l}\text { R\&D Systems, distributed by Bio-Scientific Pty Ltd, Gymea, } \\
\text { NSW, Australia }\end{array}$ \\
\hline & Tumor necrosis factor & $10 \mathrm{ng} / \mathrm{mL}$ & R\&D Systems \\
\hline \multirow[t]{2}{*}{ Stimulators } & Forskolin & $4.1 \mu \mathrm{g} / \mathrm{mL}$ & Sigma-Aldrich \\
\hline & Dibutyryladenosine cyclic monophosphate & $1 \mathrm{mM}$ & Sigma-Aldrich \\
\hline Vitamin & Retinoic acid & $3 \mu \mathrm{g} / \mathrm{mL}$ & Sigma-Aldrich \\
\hline \multirow[t]{15}{*}{ Growth factors } & Activin A & $100 \mathrm{ng} / \mathrm{mL}$ & R\&D Systems \\
\hline & Basic fibroblast growth factor & $100 \mathrm{ng} / \mathrm{mL}$ & Roche Australia Pty Ltd, Thebarton, SA, Australia \\
\hline & Bone morphogenetic protein 6 & $100 \mathrm{ng} / \mathrm{mL}$ & R\&D Systems \\
\hline & Epidermal growth factor & $10 \mathrm{ng} / \mathrm{mL}$ & Boehringer Ingelheim Pty Ltd, North Ryde, NSW, Australia \\
\hline & Fibroblast growth factor 7 & $10 \mathrm{ng} / \mathrm{mL}$ & R\&D Systems \\
\hline & Fibroblast growth factor 9 & $30 \mathrm{ng} / \mathrm{mL}$ & R\&D Systems \\
\hline & Platelet-derived growth factor & $10 \mathrm{ng} / \mathrm{mL}$ & R\&D Systems \\
\hline & Bone morphogenetic protein 15 & $100 \mathrm{ng} / \mathrm{mL}$ & R\&D Systems \\
\hline & Connective tissue growth factor & $25 \mathrm{ng} / \mathrm{mL}$ & Invitrogen/Life Technologies \\
\hline & Stem cell factor & $100 \mathrm{ng} / \mathrm{mL}$ & R\&D Systems \\
\hline & Transforming growth factor beta 1 & $10 \mathrm{ng} / \mathrm{mL}$ & R\&D Systems \\
\hline & Vascular endothelial growth factor & $10 \mathrm{ng} / \mathrm{mL}$ & R\&D Systems \\
\hline & Glial-derived factor $9^{\circ}$ & $100 \mathrm{ng} / \mathrm{mL}$ & R\&D Systems \\
\hline & Glial-cell-derived neurotrophic factor & $100 \mathrm{ng} / \mathrm{mL}$ & R\&D Systems \\
\hline & Leukemia inhibitory factor & $10^{3} \mathrm{U} / \mathrm{mL}$ & Sigma-Aldrich \\
\hline
\end{tabular}


The wells were washed with $1 \mathrm{X}$ PBS, and subsequently different chemical treatments were added. All treatments were prepared in DMEM/F12 medium containing 1\% FCS, 1\% penicillin and streptomycin sulfate, and $0.1 \%$ fungizone. After $18 \mathrm{~h}$, the cells were harvested for RNA extraction by lysis in $500 \mu \mathrm{L}$ TRIzol (Ambion/Life Technologies) each and stored at $-80^{\circ} \mathrm{C}$. To limit the number of samples for the qRT-PCR, the treatments were used at concentrations previously reported in the literature instead of dose-response experiments for each of the 31 agents (Table 1 ).

\section{Treatment of bovine fibroblast cultures with TGFB1 and TGFB inhibitor SB431542}

Bovine fetal fibroblasts ( $n=5$ for weeks $9-15$ in the first trimester, $n=6$ for weeks $19-26$ in the second trimester) were seeded at 30,000 cells/well in 24 well plates in DMEM/F12 medium containing 5\% FCS, $1 \%$ penicillin and streptomycin sulfate and $0.1 \%$ fungizone, and incubated for $24 \mathrm{~h}$ at $38.5^{\circ} \mathrm{C}$ and $5 \% \mathrm{CO}_{2}$ until $60-70 \%$ confluence. After $24 \mathrm{~h}$, the wells were washed with $1 X$ PBS and immediately treated with $5 \mathrm{ng} / \mathrm{mL}$ or $20 \mathrm{ng} / \mathrm{mL}$ TGF $\beta-1$ with or without the TGF $\beta$ inhibitor SB431542 $(10 \mu \mathrm{M}$, dissolved in DMSO, Sigma-Aldrich) in DMEM/F12 medium containing 1\% FCS, 1\% penicillin and streptomycin sulfate and $0.1 \%$ fungizone. DMSO $(0.78 \%)$, the vehicle for SB431542, was added to the control wells and the wells treated with TGF $\beta$-1 alone. After $18 \mathrm{~h}$, the cells were harvested for RNA.

\section{Culture of bovine ovarian tissue slices}

Bovine fetal ovaries ( $n=4$ 12-18weeks) were excised into two portions; one portion was stored at $-80^{\circ} \mathrm{C}(0 \mathrm{~h}$ tissue) for subsequent RNA extraction and the second portion was cultured in DMEM/F12 medium containing 5\% FCS, 1\% penicillin and streptomycin sulfate and $0.1 \%$ fungizone, and incubated for $24 \mathrm{~h}$ at $38.5^{\circ} \mathrm{C}$ and $5 \% \mathrm{CO}_{2}$. After $24 \mathrm{~h}$, the ovarian tissue slices were collected and frozen at $-80^{\circ} \mathrm{C}$ for RNA extraction.

\section{Treatment of human fetal ovarian fibroblasts with $T G F \beta-1$, activin $A$ and $S B 431542$}

Human fetal ovarian fibroblasts $(n=3, \quad 15-17$ weeks gestation) were cultured in $75 \mathrm{~cm}^{2}$ tissue culture flasks until subconfluence. Cells were then seeded in culture medium in 6 or 12 well plates at $37^{\circ} \mathrm{C}$ for $7 \mathrm{~h}$. Once $70 \%$ confluent, the cells were washed and serum-starved overnight in culture medium containing only $1 \%$ FCS. The next day, the medium was replaced with fresh culture medium containing $1 \%$ FCS and the relevant treatments or vehicle; $5 \mathrm{ng} / \mathrm{mL}$ TGF $\beta-1,100 \mathrm{ng} / \mathrm{mL}$ activin $\mathrm{A}$ and $10 \mu \mathrm{M}$ SB431542. The cells were incubated at $37^{\circ} \mathrm{C}$ for $24 \mathrm{~h}$ and then harvested for RNA extraction.

\section{RNA extraction and CDNA synthesis}

For our bovine study, the ovarian tissue samples previously frozen were homogenized in $1 \mathrm{~mL}$ TRIzol with $0.5 \mathrm{~g}$ ceramic beads in homogenization tubes using the Mo Bio PowerLyzer
24 (Mo Bio Laboratories Inc, Carlsbad, CA, USA). The cells previously harvested for RNA and the homogenized tissue samples underwent further treatment for RNA extraction as per manufacturer's instructions (Ambion/Life Technologies). Using a Nanodrop spectrophotometer (NanoDrop 1000 3.7.1, Thermo Fisher Scientific), the RNA concentrations were determined based on the $260 \lambda$ (wavelength) absorbance. All samples had a 260/280 $\lambda$ absorbance ratio $>1.8$ indicating sufficient RNA purity for analysis. Two hundred nanograms of each DNAse-treated RNA underwent cDNA synthesis as described in a previous study (Matti et al. 2010).

For the human samples, RNA was extracted from cells using the RNeasy Micro Kit (Qiagen) with on-column DNase I digestion as per manufacturer's instructions. After quantification on a Nanodrop spectrophotometer, reverse transcription was carried out using $200 \mathrm{ng}$ RNA/reaction with the Maxima First Strand cDNA synthesis kit (Thermo Fisher Scientific).

\section{Quantitative real-time PCR}

Quantitative real-time PCR of the bovine samples for the target genes FBN1, FBN2 and FBN3 and the housekeeping gene $18 \mathrm{~S}$ was performed using a Rotor-Gene 6000 series 1.7 thermal cycler (Corbett Life Science, Concord, NSW, Australia). cDNA dilutions were amplified in $10 \mu \mathrm{L}$ reactions containing $5 \mu \mathrm{L}$ Power SYBR Green PCR Master Mix (Applied Biosystems/ Life Technologies), $0.1 \mu \mathrm{L}$ each of reverse and forward primers (Geneworks; Table 2) respectively for the genes of interest, $1 \mu \mathrm{L}$ of the 1:100 cDNA dilution (for the housekeeping gene 185 ) or 1:10 cDNA dilution (for $F B N 1, F B N 2, F B N 3$ ) and $3.8 \mu \mathrm{L}$ DEPC-treated water. PCR amplification of the cDNA samples was carried out in duplicates at $95^{\circ} \mathrm{C}$ for $15 \mathrm{~s}$, followed by $60^{\circ} \mathrm{C}$ for $60 \mathrm{~s}$ for 40 cycles. The Rotor-Gene 6000 software (Q Series, Qiagen) was used to determine the cycle threshold $(\mathrm{Ct})$ values at a threshold of 0.05 normalized fluorescence units. Gene expression was determined by the mean of $2^{-\Delta \mathrm{Ct}}$, where $\Delta \mathrm{Ct}$ represents the target gene $\mathrm{Ct}-18 \mathrm{~S} \mathrm{Ct}$. The standard error of the mean $( \pm$ S.E.M.) for the power calculation was determined

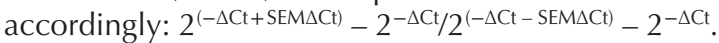

Gene expression in human fetal ovaries and ovarian cell cultures was analyzed by qRT-PCR using the ABI7900 Fast system with SDS2.4 software (Life Technologies) and Brilliant III SYBR Green Master Mix (Agilent Technologies), with melt curve analysis as described previously (Bayne et al. 2015). Primers used for the qRT-PCR are shown in Table 2.

\section{Statistical analyses}

All statistical calculations were performed using Microsoft Office Excel 2010 (Microsoft) and GraphPad Prism version 6.00 (GraphPad Software). For the treatment experiments on bovine and human samples, statistical comparisons of the $\Delta \mathrm{Ct}$ data between the untreated control and the treatments for each fetal fibroblast sample were conducted using log transformed data where appropriate by ANOVA with Dunnett's post hoc test and a value of $P<0.05$ was considered significant. For the bovine ovarian tissue culture experiment, statistical comparisons of the $\Delta \mathrm{Ct}$ data between the $0 \mathrm{~h}$ tissue and the $24 \mathrm{~h}$ cultured tissue for each fetal ovary 


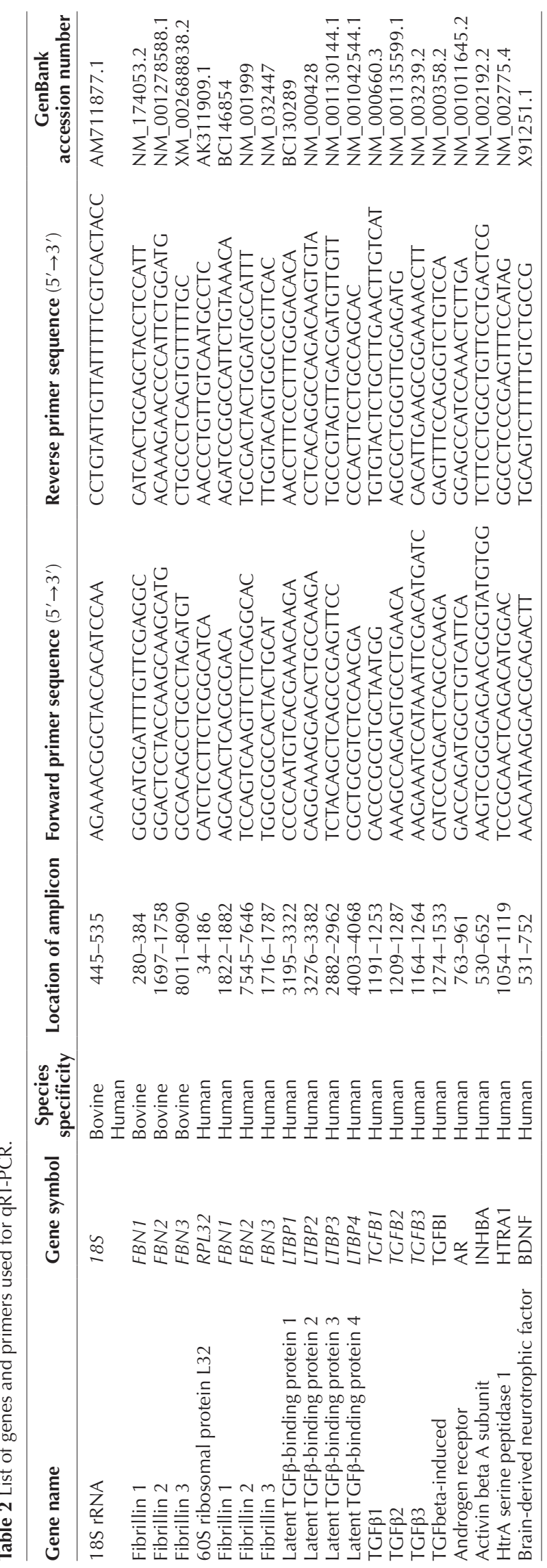

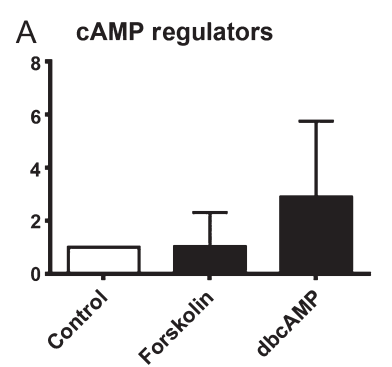
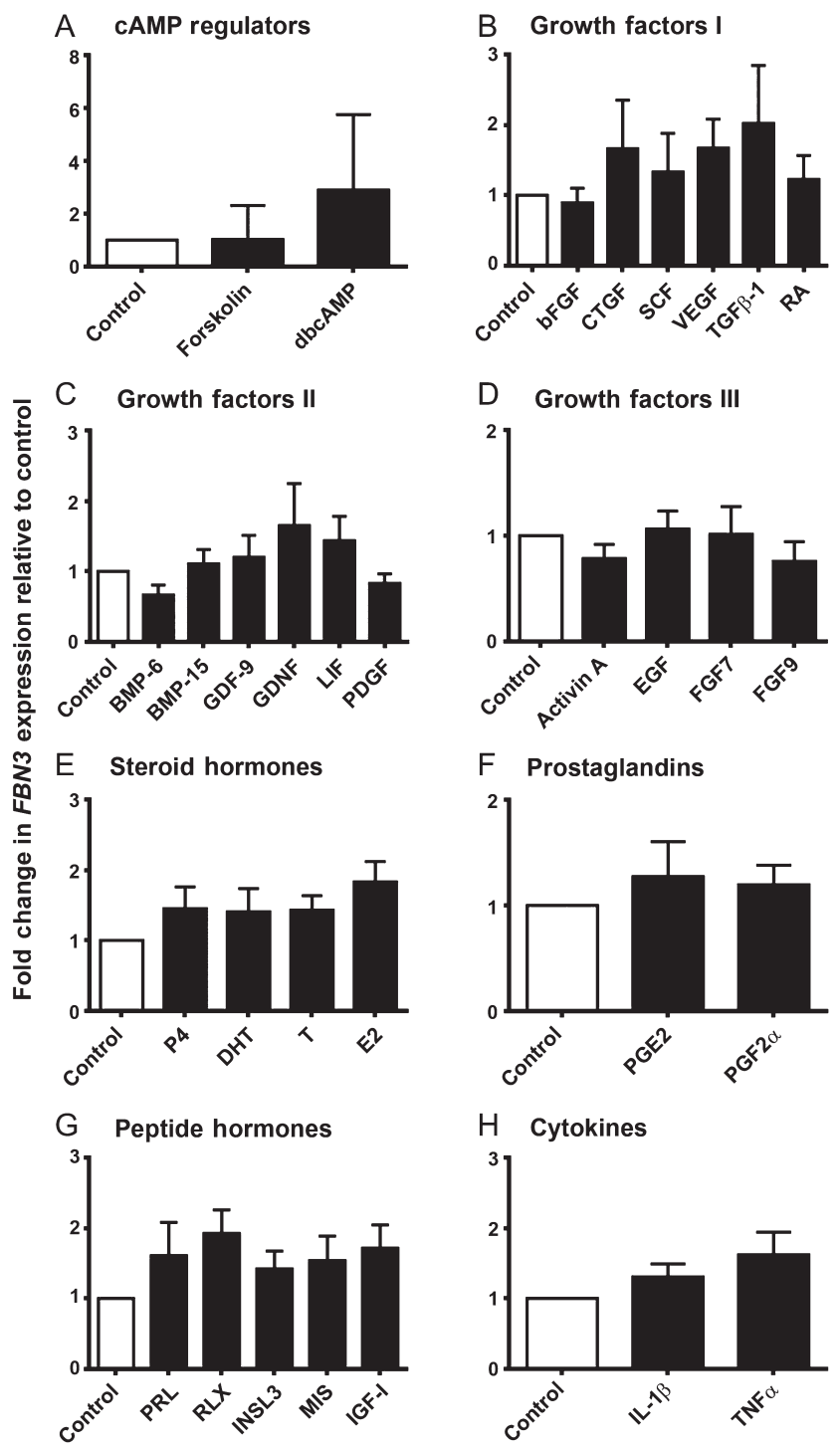

Figure 1 Expression of $F B N 3$ in bovine fetal fibroblasts from different gestational ages cultured in the presence of 31 different chemical agents grouped as indicated ( $\mathrm{A}$ to $\mathrm{H}$ ) for $18 \mathrm{~h}$. The data are shown as mean \pm S.E.M. of fold change in $F B N 3$ expression relative to the untreated control ( $n=5$ ovaries, each from 13, 14, 17, 19 and 33 weeks of gestation, respectively).

sample were conducted by unpaired $T$-tests and a value of $P<0.05$ was considered significant.

\section{Results}

\section{Screening for possible regulators of $F B N 3$}

To identify possible regulators of $F B N 3$, we treated bovine fetal ovarian fibroblasts ( $n=5$ ovaries, each from 13, $14,17,19$ and 33 weeks of gestation) with 31 different reagents (Table 1) for $18 \mathrm{~h}$ and observed their effects on FBN3 expression (Fig. 1). The range of treatments used included CAMP regulators, growth factors, steroid hormones, peptide hormones, prostaglandins and 
cytokines, previously shown to play roles in adult ovarian function, such as cell proliferation and extracellular matrix production. No substantial effects were seen in any individual culture and the data were therefore combined across the gestational ages for statistical analyses, which showed that there were no significant differences in FBN3 expression between the control and any of the treated cultures. Furthermore, we also observed that the expression of $F B N 3$ in these cultures was very low.

\section{Treatment of bovine fetal fibroblasts with TGFB-1 and TGFB-inhibitor SB431542}

A partial dose-response experiment was carried out using 5 or $20 \mathrm{ng} / \mathrm{mL}$ TGF $\beta-1$ with or without the TGF $\beta$-signaling inhibitor SB431542, which selectively inhibits the TGF $\beta$ superfamily type I activin receptorlike kinase $(A L K)$ receptors ALK4, ALK5 and ALK7 (Inman et al. 2002a), using fetal ovarian fibroblast cultures ( $n=5$ ovaries from weeks $9-15$ in first trimester; $n=6$ ovaries from weeks $19-26$ in the second trimester). Gene expression analyses showed that the expression of $F B N 1$ in fetal ovarian fibroblasts from 9-15 weeks of gestation was not significantly

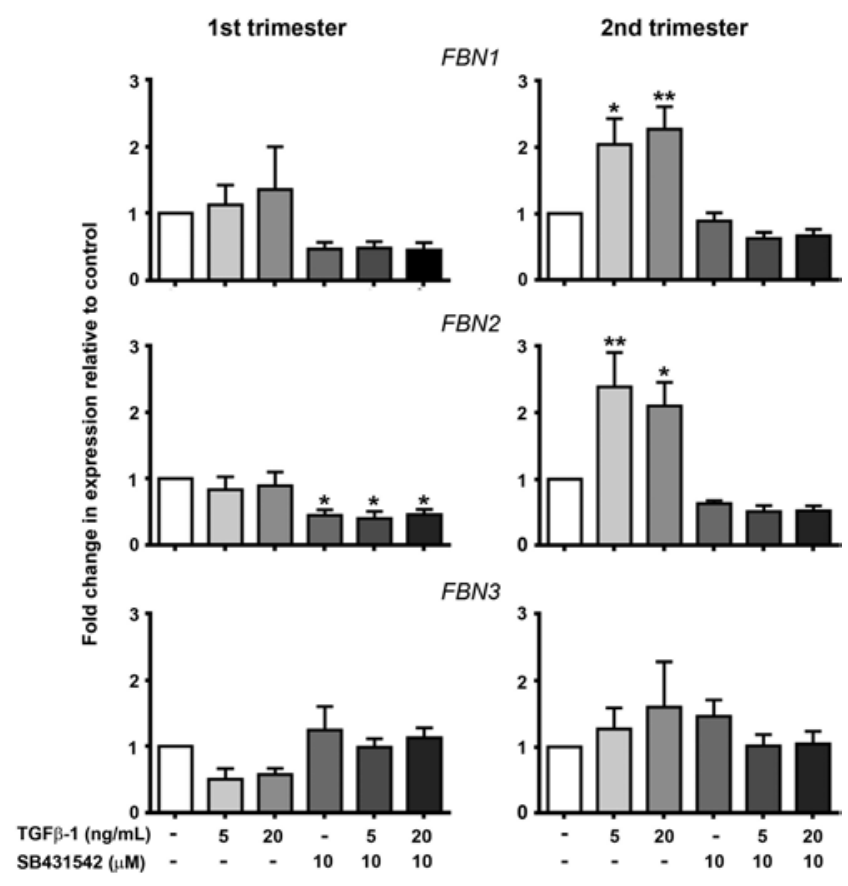

Figure 2 Expression of $F B N 1-3$ in bovine fetal fibroblasts from the first and second trimester of gestation cultured in the presence of 5 and $20 \mathrm{ng} / \mathrm{mL}$ TGF $\beta-1$ with and without $10 \mu \mathrm{M} \mathrm{SB} 431542$ for $18 \mathrm{~h}$.

The data are shown as mean \pm S.E.M. of fold change in $F B N 1-3$ expression relative to the untreated control $(n=5$ ovaries from weeks 9-15 in the first trimester; $n=6$ ovaries from weeks $19-26$ in the second trimester). Significantly different results for qRT-PCR were determined by one-way ANOVA with Dunnett's post hoc test. All values which were statistically different from the control are indicated by asterisk symbols in the graphs. ${ }^{*} P<0.05,{ }^{* *} P<0.01$, significant differences.

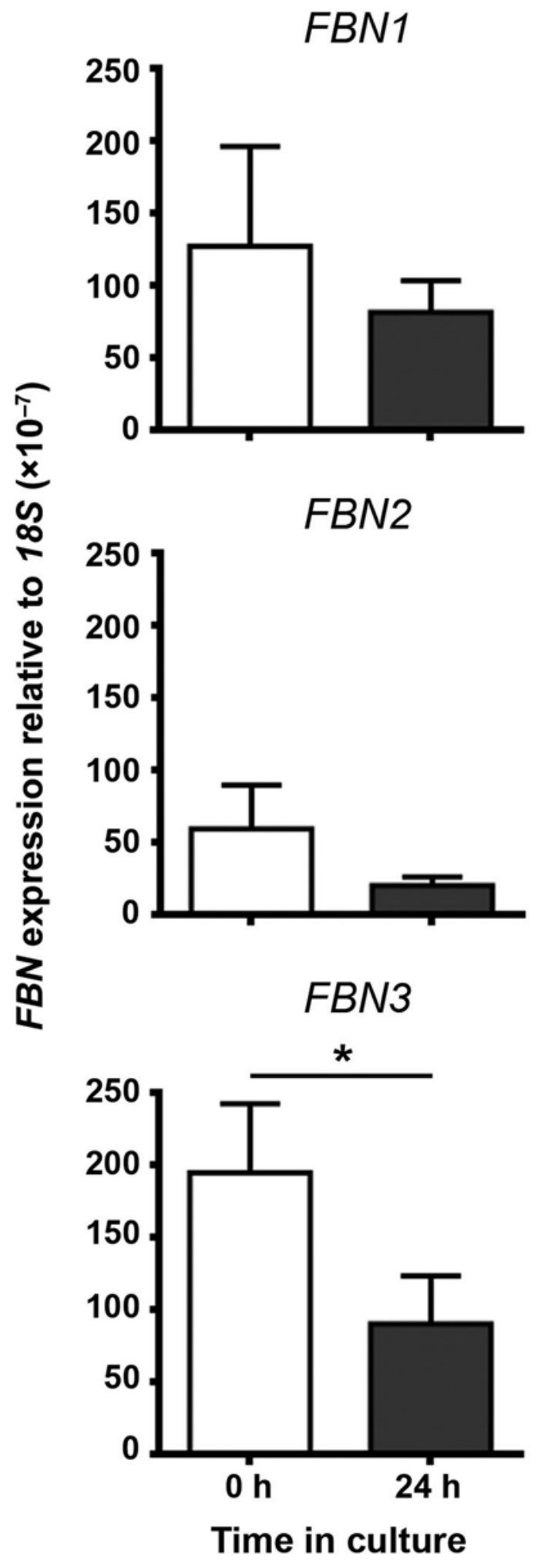

Figure 3 Expression of $F B N 1-3$ in bovine fetal ovarian tissue slices before and after 24-h culture. The data are shown as the mean \pm S.E.M. of $F B N 1-3$ expression relative to $18 S$ ( $n=1$ ovary from 12 weeks of gestation and $n=3$ ovaries from weeks 16-18). Significantly different results for qRT-PCR were determined by unpaired $t$-tests. All values that were statistically different are indicated by asterisk symbols in the graphs. ${ }^{*} P<0.05$. 

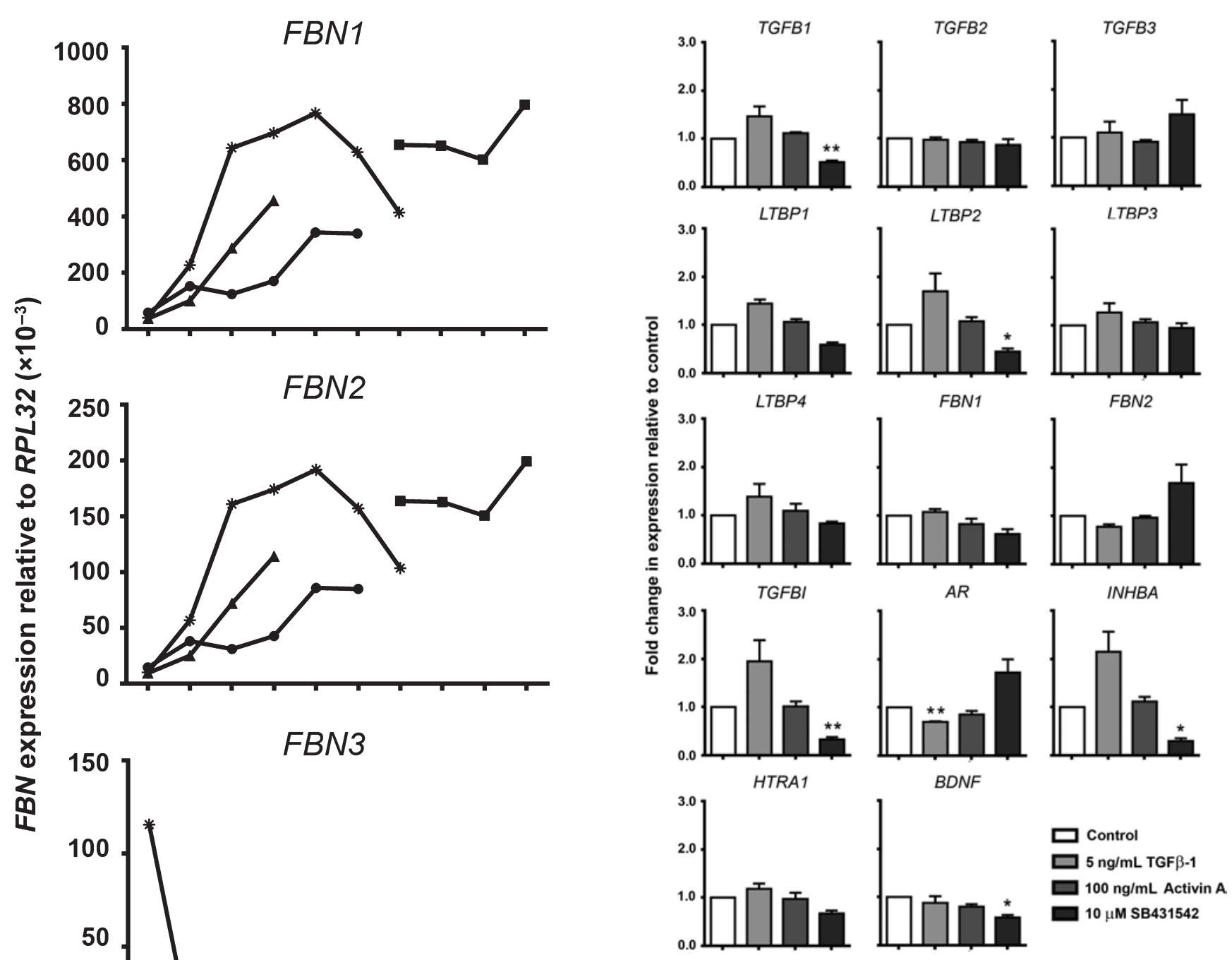

Figure 5 Expression levels of TGFB1-3, LTBP1-4, FBN1-2, TGFBI, $A R, I N H B A, H T R A 1$ and $B D N F$ in primary human fetal ovarian fibroblast cultures in the presence or absence of $5 \mathrm{ng} / \mathrm{mL}$ TGF $\beta-1$, $100 \mathrm{ng} / \mathrm{mL}$ activin A and $10 \mu \mathrm{M} \mathrm{SB} 431542$ for $24 \mathrm{~h}$. The data shown are mean \pm S.E.M. of target gene expression relative to the untreated control from 15-17 weeks gestation human fetal ovarian fibroblast cultures ( $n=3$ ovaries). Significantly different results for qRT-PCR were determined by one-way ANOVA with Dunnett's post hoc test. All values which were statistically different from the control are indicated by asterisk symbols in the graphs. ${ }^{*} P<0.05,{ }^{* *} P<0.01$, significant differences.

Figure 4 Expression levels of $F B N 1-3$ (pmol/nmol RPL32) in human fetal ovarian somatic cell/fibroblast cultures from different gestational ages from tissue digestion up to the eighth passage. T0 represents disaggregated ovarian tissue before culture and P0 represents adherent ovarian cells before the first passage. The different colored symbols represent cells from single ovaries at different gestational ages: $(*)$ represents a 9-week ovary, $(\boldsymbol{\Delta})$ represents a 15 -week ovary, (-) represents a 16-week fetal ovary, and $(\boldsymbol{\square})$ represents a 17-week fetal ovary.

affected when these cells were treated with TGF $\beta-1$ (Fig. 2). However, it was observed that compared with the untreated control, there was a significant increase in $F B N 1$ expression in the TGF $\beta$-1-treated 19-26 week fibroblasts, with the higher TGF $\beta-1$ concentration causing a more significant increase in

FBN1 expression. This effect of TGF $\beta$-1 was prevented by the antagonist SB431542, which had no effect alone. TGF $\beta-1$ did not cause a significant effect on FBN2 expression in the 9-15 week gestation cells (Fig. 2), but SB431542 caused a significant reduction in FBN2 expression, with or without TGF $\beta-1$ (Fig. 2). In later gestation, TGF $\beta-1$ stimulated $F B N 2$ expression and SB431542 inhibited this stimulation, similarly to the effect on $F B N 1$ expression. None of the treatments significantly affected $F B N 3$ expression in fibroblast cultures of either gestational age (Fig. 2). 


\section{Expression of FBN1-3 in bovine fetal ovarian tissue}

We then measured expression levels of fibrillin genes in fetal ovarian tissue slices before $(0 \mathrm{~h})$ and after culturing for $24 \mathrm{~h}$ ( $n=1$ ovary from 12 weeks of gestation and $n=3$ ovaries from weeks 16-18). There were no significant differences $(P>0.05)$ in $F B N 1$ and $F B N 2$ expression between the $0 \mathrm{~h}$ ovarian tissue and the ovarian tissue cultured for $24 \mathrm{~h}$ (Fig. 3). However, we observed a significant decline in $F B N 3$ expression by $24 \mathrm{~h}$.

\section{Expression of FBN1-3 in human fetal ovarian cells}

The expression levels of $F B N 1-3$ were analyzed in disaggregated human fetal ovarian tissue $(n=4$ ovaries from 9-17 weeks of gestational age) before culture, in adherent ovarian fibroblasts before the first passage and up to the eighth cell passage. FBN1 and FBN2 expression increased in all cultures across passages (Fig. 4). FBN3 was expressed higher in the disaggregated cells of a 9-week-old fetal ovary compared with later gestation fetal ovaries (Fig. 4). However, the ovarian cells of all fetal ovaries showed a dramatic decline in $F B N 3$ expression in culture and a loss of $F B N 3$ expression after the first passage.

\section{TGF $\beta-1$, activin $A$ and SB431542 treatment of human fetal ovarian cells}

Human fetal ovarian fibroblasts $(n=3$ ovaries from 15-17 weeks gestation) were treated with $5 \mathrm{ng} / \mathrm{mL} \mathrm{TGF} \beta-1$, $100 \mathrm{ng} / \mathrm{mL}$ activin A and $10 \mu \mathrm{M}$ SB431542 separately. TGFB1-3, LTBP1-4, FBN1-3, AR, INHBA, HTRA1 and $B D N F$ expression levels were subsequently measured. SB431542 treatment significantly lowered TGFB1, LTBP2, $T G F B I, I N H B A$ and $B D N F$ expression, whereas TGF $\beta-1$ treatment significantly reduced $A R$ expression (Fig. 5). None of the treatments significantly affected TCFB2-3, LTBP1, LTBP3-4, FBN1-2, and HTRA1 expression (Fig. 5). $F B N 3$ expression was not detectable in these cultures.

\section{Discussion}

In this study, we investigated the regulation of fibrillins and related TGF $\beta$ s and latent TGF $\beta$ binding proteins in vitro using bovine and human fetal ovaries under different culture conditions: monolayer culture, passaging of these monolayer cultures and culture of pieces of tissue. We initially carried out a screen for possible regulators of $F B N 3$. The effects of TGF $\beta$ and its pathway inhibitor SB431542 were examined in more detail and the effects on all fibrillins were examined. In humans, the effects of these and activin were also examined in detail. A consistent observation was that during culture, $F B N 3$ was downregulated and $F B N 1$ was upregulated, as occurs in vivo with increasing gestation (Hatzirodos et al. 2011).
To date, only one study has investigated the effects of TGF $\beta$ signaling on the expression of fibrillin genes in fetal tissues. This study found that TGF $\beta-1$ increased $F B N 1$ and $F B N 2$ expression in murine fetal skin (Samuel et al. 2003). Since a murine model was used for that study, an examination of the expression of $F B N 3$ was not possible, as this gene is inactivated in mice (Corson et al. 2004). In adult fibroblasts, TGF $\beta-1$ was shown to increase FBN1 and FBN2 expression (Samuel et al. 2003 ), and the involvement of the TGF $\beta$ superfamily is well characterized in ovarian follicle development (Knight \& Glister 2006). We therefore examined the effects of TGF $\beta-1$ on expression of the fibrillin genes. In the bovine study, we found that treatment with TGF $\beta-1$ caused a significant increase in $F B N 1$ and $F B N 2$ expression in the second trimester fibroblasts. These results suggest that in the bovine, TGF $\beta$ - 1 regulation of the expression of $F B N 1$ and $F B N 2$ only becomes active as development progresses. However, TGF $\beta-1$ treatment did not affect $F B N 1$ and $F B N 2$ expression in cultured human fetal ovarian fibroblasts at 15-17 weeks gestation. FBN2 has different expression profiles in the bovine and human both during gestation and in the adult ovaries (Hatzirodos et al. 2011), suggesting differential regulation in these species. Furthermore, it appears that TGF $\beta$-1 regulates $F B N 2$ expression differently in the bovine and human later in gestation.

We also examined human fetal ovarian fibroblasts from later gestation when steroidogenic enzymes are expressed (Fowler et al. 2011). We observed that TGF $\beta-1$ treatment caused a significant decrease in the expression of the androgen receptor gene $(A R)$. There are no previous studies investigating the effects of TGF $\beta$ directly on $A R$ expression. However, it is known that interaction of Smad3, a mediator of intracellular TGF $\beta$ signaling, with the androgen receptor represses AR-mediated transcription, but the exact mechanisms of this repression are not well understood (Kang et al. 2001, Chipuk et al. 2002). Treatment of monkey kidney cells and human prostate cells with TGF $\beta-1$ caused a reduction in AR-mediated transcription as indicated by luciferase reporter activity in these cells (Hayes et al. 2001). The findings of our study suggest that TGF $\beta$ signaling may repress AR-dependent transcription by inhibiting expression of the androgen receptor itself. On the other hand, we also observed significant reductions in the expression of the TCFB1, LTBP2, TGFBI, and INHBA genes when the human fetal ovarian fibroblasts were treated with the TFG $\beta$ antagonist SB431542. SB431542 selectively inhibits TGF $\beta$ type I receptors, activin-like receptor kinase 4, 5 and 7 (ALKs 4, 5 and 7) (Inman et al. 2002a). Therefore, ALK5 remains inactive (Callahan et al. 2002) and unable to phosphorylate Smads 2 and 3 (Callahan et al. 2002, Inman et al. 2002a) and the classical TGF $\beta /$ smad pathway is disrupted (Heldin et al. 1997, Inman et al. 2002b, Derynck \& Zhang 2003). TGF $\beta-1$ treatment causes a small and nonsignificant 
increase in the expression of these genes; thus, the effect of SB431542 is likely to reflect antagonism of stimulation by endogenous TGF $\beta$ signaling. Likewise, the reduction in BDNF expression with SB431542 treatment suggests that endogenous TGF $\beta$ signaling is capable of stimulating $B D N F$ expression in these cultured fibroblasts.

In culture of bovine fetal fibroblasts from the first trimester, SB431542 either alone or in combination with TGF $\beta-1$ caused a significant decrease in FBN2 expression compared with the control even though TGF $\beta-1$ had no effect on these fibroblasts. Therefore, as with the human cell experiments, we speculate that SB431542 is inhibiting endogenous TGF $\beta$ signaling via the TGF $\beta$ type I and II receptors, which is stimulatory of $F B N 2$ expression. The TGF $\beta$ superfamily ligands that bind to these receptors include TGF $\beta$ s, activins, nodal and GDF8 (myostatin) (Heldin et al. 1997, Reissmann et al. 2001, Derynck \& Zhang 2003, Rebbapragada et al. 2003). Currently, we have not identified which of these endogenous ligands are involved. On the other hand, in the second trimester bovine fibroblasts, the expression levels of $F B N 1$ and $F B N 2$ were similar to the control when SB431542 in combination with TGF $\beta-1$ was present in these cultures. Since we observed that TGF $\beta-1$ increased the expression of $F B N 1$ and $F B N 2$ in these fibroblasts, these observations suggest that SB431542 is alleviating the effects of exogenous TGF $\beta-1$, with no evidence of stimulation of the expression of these genes by endogenous TGF $\beta$. Overall, our observations show that $F B N 1$ and FBN2 are differentially regulated in both the bovine and human ovary.

To date, there have not been any studies investigating the effect of activin $A$ on the gene expression of fibrillins. However, previous studies have shown that activin A is capable of causing an increase in the proliferation of human lung fibroblasts (Heeren et al. 2015) as well as promoting proliferation of cultured rat renal interstitial fibroblasts and increasing the expression of type I collagen (Yamashita et al. 2004). We have observed that activin A did not affect the expression of $F B N 1$ or $F B N 2$ or the other TGF $\beta$-associated genes examined in our human samples. The levels of $F B N 3$ expression in the treated human fetal ovarian fibroblasts cultures were undetectable.

The fetal ovary consists of a mixture of cell types, and interactions between fibroblasts, GREL cells, pregranulosa/granulosa cells and germ cells might be required to maintain $F B N 3$ expression. The other cell types in the ovary may also be producing factors required by fibroblasts to stimulate $F B N 3$ expression. Thus, we carried out tissue culture experiments, but even a short-term culture $(24 \mathrm{~h})$ of bovine fetal ovarian tissue sections, which represent a cross section of the three-dimensional ovarian structure containing all cell types and its extracellular matrix, showed a decline in the expression of $F B N 3$. Similarly, we observed a drastic decline in $F B N 3$ expression but an increase in FBN1 and FBN2 expression in the cultured human fetal ovarian fibroblasts, consistent with development of a more mature phenotype in culture. This indicates very stringent and possibly complex regulation of $F B N 3$ expression in vivo, which is not maintained in vitro, limiting our ability to study the expression of this gene.

A previous study showed that ovarian $F B N 2$ and FBN3 are fetal fibrillins (Hatzirodos et al. 2011). FBN3 is initially expressed highly and then begins to decline at the end of the first trimester and FBN2 declines sometime between the fetal stages and adulthood at least in human (Hatzirodos et al. 2011). FBN1 persists through fetal ovary development and is increased in the adult ovary (Hatzirodos et al. 2011) - it is an adult fibrillin. These data therefore imply that the three fibrillin genes have independent regulatory mechanisms to account for their different expression profiles in the bovine and human. This is also supported by the study of Davis et al. (2014), which found that there was little overlap in the transcription factor motifs present on the human $F B N 3$ promoter and those of $F B N 1$ and 2 promoters, suggesting that these genes are differentially regulated and differentially expressed (Davis et al. 2014).

In summary, FBN3 expression is rapidly reduced in both cell and tissue culture, and was not maintained or stimulated by a range of growth factors. This study has also shown that in the bovine, there is differential regulation of $F B N 1$ and $F B N 2$ between the early and later stages of gestation, which is partially mediated through the signaling pathways involving either ALK 4,5 or 7 . TGF $\beta$ regulates its own signaling both directly through $T C F \beta$ expression and through regulation of expression of other binding proteins such as $L T B P 2$. These data therefore demonstrate that the regulation of TGF $\beta$ signaling appears to change during fetal ovarian development.

\section{Declaration of interest}

The authors declare that there is no conflict of interest that could be perceived as prejudicing the impartiality of the research reported.

\section{Funding}

Funding support for this research was obtained from the National Health and Medical Research Council of Australia, the University of Adelaide, the Clive and Vera Ramaciotti Foundation, the Wellcome Trust, the National Institute of Health and the Medical Research Council UK (G1100357).

\section{Authors' contribution statement}

N A B, K H, N H, W M B, M D H, H F I-R and R J R were responsible for planning the experiments on bovine samples, conducting cell culture and treatment experiments, RT-PCR, data analysis and interpretation as well as revising the manuscript. R A B and R A A conducted cell culture and treatment experiments on human samples, RT-PCR, data analysis and reviewed the manuscript. 


\section{Acknowledgments}

We would like to thank Mrs Wendy Bonner for the collection of bovine fetal ovaries from the abattoir and Thomas Foods International, Murray Bridge, SA, for the supply of bovine fetal ovaries. We also thank Anne Saunderson and the staff of the Bruntsfield Suite, Royal Infirmary of Edinburgh for patient recruitment.

\section{References}

Bayne RA, Kinnell HL, Coutts SM, He J, Childs AJ \& Anderson RA 2015 GDF9 is transiently expressed in oocytes before follicle formation in the human fetal ovary and is regulated by a novel NOBOX transcript. PLoS ONE 10 e0119819. (doi:10.1371/journal.pone.0119819)

Birchmeier C \& Birchmeier W 1993 Molecular aspects of mesenchymalepithelial interactions. Annual Review of Cell and Developmental Biology 9 511-540. (doi:10.1146/annurev.cb.09.110193.002455)

Callahan JF, Burgess JL, Fornwald JA, Gaster LM, Harling JD, Harrington FP, Heer J, Kwon C, Lehr R, Mathur A et al. 2002 Identification of novel inhibitors of the transforming growth factor beta1 (TGF-beta1) type 1 receptor (ALK5). Journal of Medicinal Chemistry 45 999-1001. (doi:10.1021/jm010493y)

Chaudhry SS, Cain SA, Morgan A, Dallas SL, Shuttleworth CA \& Kielty CM 2007 Fibrillin-1 regulates the bioavailability of TGFbeta1. Journal of Cell Biology 176 355-367. (doi:10.1083/jcb.200608167)

Chen MM, Lam A, Abraham JA, Schreiner GF \& Joly AH 2000 CTGF expression is induced by TGF- beta in cardiac fibroblasts and cardiac myocytes: a potential role in heart fibrosis. Journal of Molecular and Cellular Cardiology 32 1805-1819. (doi:10.1006/jmcc.2000.1215)

Chipuk JE, Cornelius SC, Pultz NJ, Jorgensen JS, Bonham MJ, Kim SJ \& Danielpour D 2002 The androgen receptor represses transforming growth factor-beta signaling through interaction with Smad3. Journal of Biological Chemistry 277 1240-1248. (doi:10.1074/jbc.M108855200)

Christner PJ \& Ayitey S 2006 Extracellular matrix containing mutated fibrillin-1 (Fbn1) down regulates Col1a1, Col1a2, Col3a1, Col5a1, and Col5a2 mRNA levels in Tsk/+ and Tsk/Tsk embryonic fibroblasts. Amino Acids 30 445-451. (doi:10.1007/s00726-005-0265-y)

Corson GM, Charbonneau NL, Keene DR \& Sakai LY 2004 Differential expression of fibrillin-3 adds to microfibril variety in human and avian, but not rodent, connective tissues. Genomics 83 461-472. (doi:10.1016/j.ygeno.2003.08.023)

Davis MR, Andersson R, Severin J, de Hoon M, Bertin N, Baillie JK, Kawaji H, Sandelin A, Forrest AR, Summers KM et al. 2014 Transcriptional profiling of the human fibrillin/LTBP gene family, key regulators of mesenchymal cell functions. Molecular Genetics and Metabolism 112 73-83. (doi:10.1016/j.ymgme.2013.12.006)

Derynck R \& Zhang YE 2003 Smad-dependent and Smad-independent pathways in TGF-beta family signalling. Nature 425 577-584. (doi:10.1038/nature02006)

Fine A \& Goldstein RH 1987 The effect of transforming growth factor-beta on cell proliferation and collagen formation by lung fibroblasts. Journal of Biological Chemistry 262 3897-3902.

Fowler PA, Anderson RA, Saunders PT, Kinnell H, Mason JI, Evans DB, Bhattacharya S, Flannigan S, Franks S, Monteiro A et al. 2011 Development of steroid signaling pathways during primordial follicle formation in the human fetal ovary. Journal of Clinical Endocrinology \& Metabolism 96 1754-1762. (doi:10.1210/jc.2010-2618)

Hatzirodos N, Bayne RA, Irving-Rodgers HF, Hummitzsch K, Sabatier L, Lee S, Bonner W, Gibson MA, Rainey WE, Carr BR et al. 2011 Linkage of regulators of TGF-beta activity in the fetal ovary to polycystic ovary syndrome. FASEB Journal 25 2256-2265. (doi:10.1096/fj.11-181099)

Hayes SA, Zarnegar M, Sharma M, Yang F, Peehl DM, ten Dijke P \& Sun Z 2001 SMAD3 represses androgen receptor-mediated transcription. Cancer Research $612112-2118$.

Heeren AM, van Iperen L, Klootwijk DB, de Melo Bernardo A, Roost MS, Gomes Fernandes MM, Louwe LA, Hilders CG, Helmerhorst FM, van der Westerlaken LA et al. 2015 Development of the follicular basement membrane during human gametogenesis and early folliculogenesis. BMC Developmental Biology 15 4. (doi:10.1186/s12861-015-0054-0)
Heldin CH, Miyazono K \& ten Dijke P 1997 TGF-beta signalling from cell membrane to nucleus through SMAD proteins. Nature 390 465-471. (doi:10.1038/37284)

Hughesdon PE 1982 Morphology and morphogenesis of the Stein-Leventhal ovary and of so-called "hyperthecosis". Obstetrical and Gynecological Survey 37 59-77. (doi:10.1097/00006254-198202000-00001)

Hummitzsch K, Irving-Rodgers HF, Hatzirodos N, Bonner W, Sabatier L, Reinhardt DP, Sado Y, Ninomiya Y, Wilhelm D \& Rodgers RJ 2013 A new model of development of the mammalian ovary and follicles. PLoS ONE 8 e55578. (doi:10.1371/journal.pone.0055578)

Hummitzsch K, Anderson RA, Wilhelm D, Wu J, Telfer EE, Russell DL, Robertson SA \& Rodgers RJ 2015 Stem cells, progenitor cells, and lineage decisions in the ovary. Endocrine Reviews 36 65-91. (doi:10.1210/ er.2014-1079)

Inman GJ, Nicolas FJ, Callahan JF, Harling JD, Gaster LM, Reith AD, Laping NJ \& Hill CS 2002a SB-431542 is a potent and specific inhibitor of transforming growth factor-beta superfamily type I activin receptor-like kinase (ALK) receptors ALK4, ALK5, and ALK7. Molecular Pharmacology 62 65-74.

Inman GJ, Nicolas FJ \& Hill CS $2002 b$ Nucleocytoplasmic shuttling of Smads 2, 3, and 4 permits sensing of TGF-beta receptor activity. Molecular Cell 10 283-294. (doi:10.1016/S1097-2765(02)00585-3)

Isogai Z, Ono RN, Ushiro S, Keene DR, Chen Y, Mazzieri R, Charbonneau NL, Reinhardt DP, Rifkin DB \& Sakai LY 2003 Latent transforming growth factor beta-binding protein 1 interacts with fibrillin and is a microfibril-associated protein. Journal of Biological Chemistry 278 2750-2757. (doi:10.1074/jbc.M209256200)

Ito Y, Aten J, Bende RJ, Oemar BS, Rabelink TJ, Weening JJ \& Goldschmeding R 1998 Expression of connective tissue growth factor in human renal fibrosis. Kidney International 53 853-861. (doi:10.1111/ j.1523-1755.1998.00820.x)

Kang HY, Lin HK, Hu YC, Yeh S, Huang KE \& Chang C 2001 From transforming growth factor-beta signaling to androgen action: identification of Smad3 as an androgen receptor coregulator in prostate cancer cells. PNAS 98 3018-3023. (doi:10.1073/pnas.061305498)

Knight PG \& Glister C 2006 TGF-beta superfamily members and ovarian follicle development. Reproduction 132 191-206. (doi:10.1530/ rep.1.01074)

Leask A \& Abraham DJ 2004 TGF-beta signaling and the fibrotic response. FASEB Journal 18 816-827. (doi:10.1096/fj.03-1273rev)

Matti N, Irving-Rodgers HF, Hatzirodos N, Sullivan TR \& Rodgers RJ 2010 Differential expression of focimatrix and steroidogenic enzymes before size deviation during waves of follicular development in bovine ovarian follicles. Molecular and Cellular Endocrinology 321 207-214. (doi:10.1016/j.mce.2010.02.019)

Nelson VL, Legro RS, Strauss JF 3rd \& McAllister JM 1999 Augmented androgen production is a stable steroidogenic phenotype of propagated theca cells from polycystic ovaries. Molecular Endocrinology 13 946-957. (doi:10.1210/mend.13.6.0311)

Polla AS, Polla LL \& Polla BS 2003 Iron as the malignant spirit in successful ageing. Ageing Research Reviews 2 25-37. (doi:10.1016/S15681637(02)00048-X)

Raja-Khan N, Urbanek M, Rodgers RJ \& Legro RS 2014 The role of TGFbeta in polycystic ovary syndrome. Reproductive Sciences 21 20-31. (doi:10.1177/1933719113485294)

Ramirez F \& Pereira L 1999 The fibrillins. International Journal of Biochemistry and Cell Biology 31 255-259. (doi:10.1016/S13572725(98)00109-5)

Rebbapragada A, Benchabane H, Wrana JL, Celeste AJ \& Attisano L 2003 Myostatin signals through a transforming growth factor beta-like signaling pathway to block adipogenesis. Molecular and Cellular Biology 23 7230-7242. (doi:10.1128/MCB.23.20.72307242.2003)

Reissmann E, Jornvall H, Blokzijl A, Andersson O, Chang C, Minchiotti G, Persico MG, Ibanez CF \& Brivanlou AH 2001 The orphan receptor ALK7 and the Activin receptor ALK4 mediate signaling by Nodal proteins during vertebrate development. Genes \& Development 15 2010-2022. (doi:10.1101/gad.201801)

Roberts AB, Sporn MB, Assoian RK, Smith JM, Roche NS, Wakefield LM, Heine UI, Liotta LA, Falanga V, Kehrl JH et al. 1986 Transforming growth factor type beta: rapid induction of fibrosis and angiogenesis in vivo and stimulation of collagen formation in vitro. PNAS 83 4167-4171. (doi:10.1073/pnas.83.12.4167) 
Rock JR, Barkauskas CE, Cronce MJ, Xue Y, Harris JR, Liang J, Noble PW \& Hogan BL 2011 Multiple stromal populations contribute to pulmonary fibrosis without evidence for epithelial to mesenchymal transition. PNAS 108 E1475-E1483. (doi:10.1073/pnas.1117988108)

Russe I 1983 Oogenesis in cattle and sheep. Bibliotheca Anatomica 24 77-92.

Sabatier L, Miosge N, Hubmacher D, Lin G, Davis EC \& Reinhardt DP 2010 Fibrillin-3 expression in human development. Matrix Biology 30 43-52. (doi:10.1016/j.matbio.2010.10.003)

Saharinen J, Hyytiainen M, Taipale J \& Keski-Oja J 1999 Latent transforming growth factor-beta binding proteins (LTBPs) - structural extracellular matrix proteins for targeting TGF-beta action. Cytokine \& Growth Factor Reviews 10 99-117. (doi:10.1016/S1359-6101(99)00010-6)

Samuel CS, Sakai LY \& Amento EP 2003 Relaxin regulates fibrillin 2, but not fibrillin 1, mRNA and protein expression by human dermal fibroblasts and murine fetal skin. Archives of Biochemistry and Biophysics 411 47-55. (doi:10.1016/S0003-9861(02)00710-5)

Saxen L \& Sariola H 1987 Early organogenesis of the kidney. Pediatric Nephrology 1 385-392. (doi:10.1007/BF00849241)

Taipale J, Miyazono K, Heldin CH \& Keski-Oja J 1994 Latent transforming growth factor-beta 1 associates to fibroblast extracellular matrix via latent TGF-beta binding protein. Journal of Cell Biology 124 171-181. (doi:10.1083/jcb.124.1.171)

Urbanek M, Sam S, Legro RS \& Dunaif A 2007 Identification of a polycystic ovary syndrome susceptibility variant in fibrillin-3 and association with a metabolic phenotype. Journal of Clinical Endocrinology \& Metabolism 92 4191-4198. (doi:10.1210/jc.2007-0761)

Varga J, Rosenbloom J \& Jimenez SA 1987 Transforming growth factor beta (TGF beta) causes a persistent increase in steady-state amounts of type I and type III collagen and fibronectin mRNAs in normal human dermal fibroblasts. Biochemical Journal 247 597-604. (doi:10.1042/bj2470597)

Wong T, McGrath JA \& Navsaria H 2007 The role of fibroblasts in tissue engineering and regeneration. British Journal of Dermatology 1561149 1155. (doi:10.1111/j.1365-2133.2007.07914.x)

Yamashita S, Maeshima A, Kojima I \& Nojima Y 2004 Activin A is a potent activator of renal interstitial fibroblasts. Journal of the American Society of Nephrology 15 91-101. (doi:10.1097/01.ASN. 0000103225.68136.E6)

Zilberberg L, Todorovic V, Dabovic B, Horiguchi M, Courousse T, Sakai LY \& Rifkin DB 2012 Specificity of latent TGF-beta binding protein (LTBP) incorporation into matrix: role of fibrillins and fibronectin. Journal of Cellular Physiology 227 3828-3836. (doi:10.1002/jcp.v227.12)

Received 29 March 2016

First decision 30 April 2016

Revised manuscript received 4 May 2016

Accepted 23 May 2016 